Supporting Information

\title{
Allosteric Inhibition of the Epidermal Growth Factor Receptor
}

Julie K.L. Sinclair ${ }^{1}$, Wesley E. Robertson ${ }^{2}$, Deepto Mozumdar ${ }^{1,3}$, Kim Quach $^{1}$ \& Alanna Schepartz ${ }^{3,4 *}$

${ }^{1}$ Department of Chemistry, Yale University, New Haven, CT 06520, ${ }^{2}$ Department of Chemistry and Molecular, Cellular, and Developmental Biology, Yale University, New Haven, CT 06520, ${ }^{3}$ Department of Chemistry, University of California, Berkeley, CA 94705, ${ }^{4}$ Department of Molecular and Cell Biology, University of California, Berkeley, CA 94705

*to whom correspondence should be addressed. Email: schepartz@berkeley.edu

\section{Table of Contents}

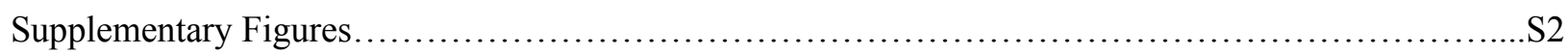

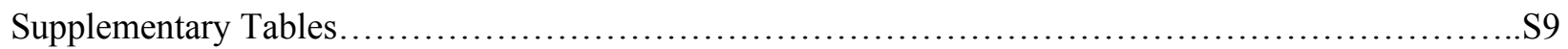

Supplementary Experimental Procedures................................................. 14

Peptide Synthesis, Purification, and Characterization................................ 14

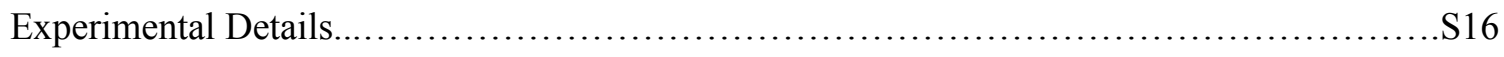

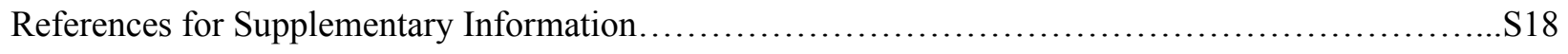


Supplementary Figures
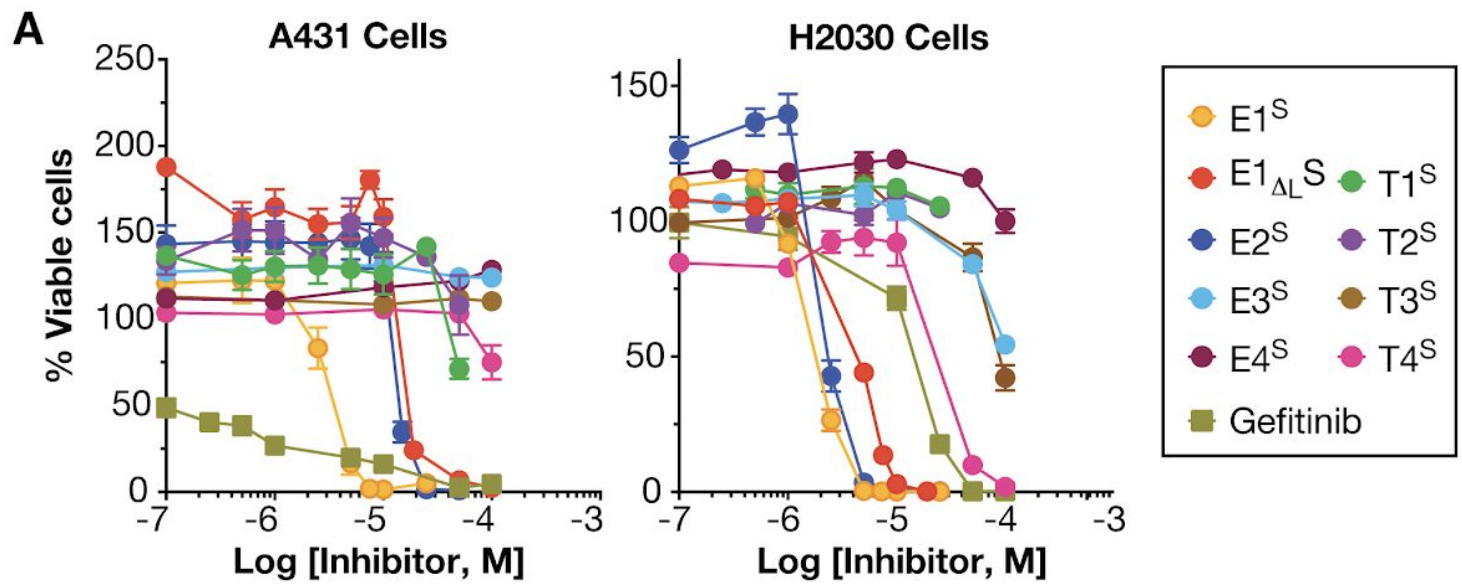

B
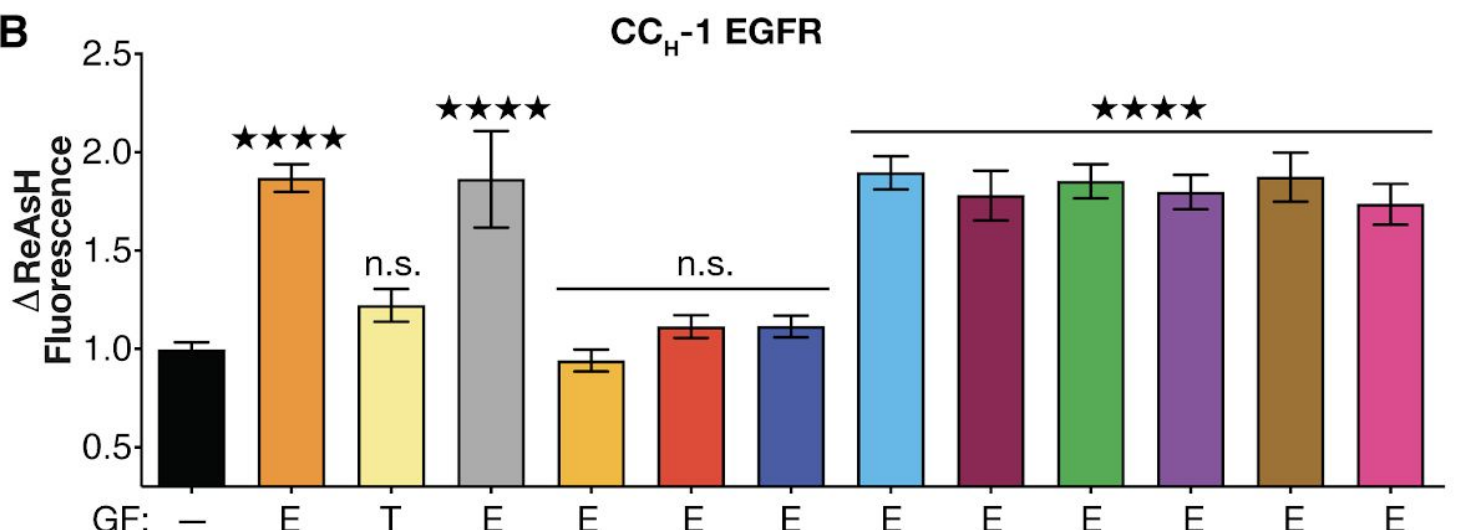

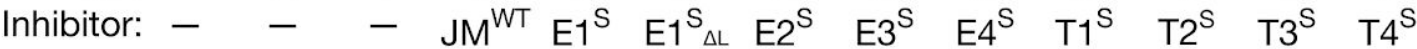

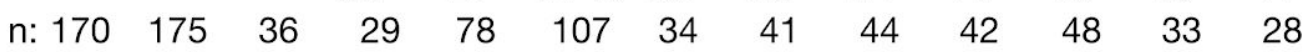

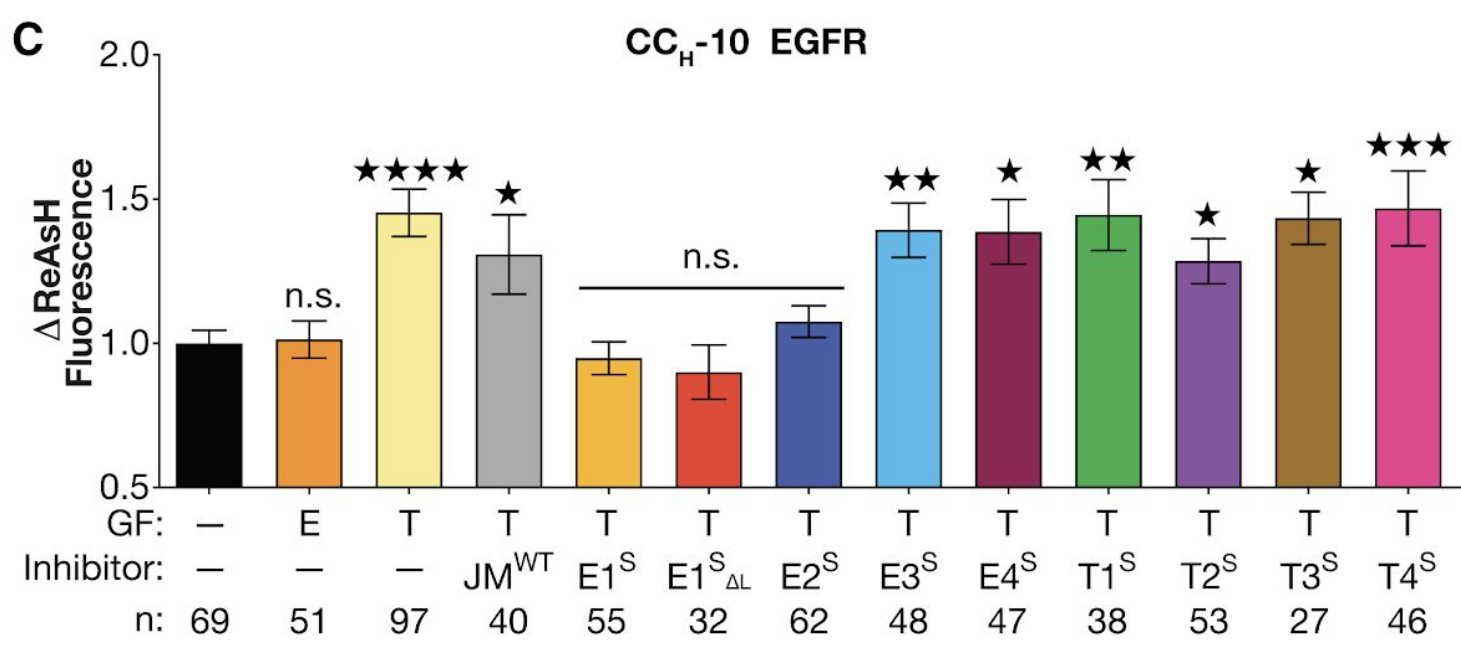

Figure S1, Related to Figure 1. Effect of hydrocarbon-stapled peptides on viability of EGFR expressing cells and JM coiled coil formation. (A) Effect of hydrocarbon-stapled peptides on A431 or H2030 cell 
proliferation. Plot illustrates the percent viable A431 or H2030 cells remaining after $18 \mathrm{~h}$ treatment with the concentration of peptide $\left(\mathrm{JM}^{\mathrm{WT}}\right)$ or hydrocarbon-stapled peptide shown. Viability was assessed by monitoring oxyluciferin production by Ultra-Glow luciferase, a reaction that requires ATP (Promega, CellTiterGlo Luminescence Assay). Dose response curves were plotted using Prism 5.0. $\mathrm{IC}_{50}$ values were calculated with a 4PL nonlinear regression, as described in the Supplemental Procedures. Error bars, s.e.m. of at least three replicates. (B and C) Effect of hydrocarbon-stapled peptides on JM coiled coil formation as determined using bipartite tetracysteine display. CHO-K1 cells were transfected with plasmids encoding either (B) EGFR $\mathrm{CC}_{\mathrm{H}}-1$, which reports on formation of the EGF-type coiled coil or (C) EGFR $\mathrm{CC}_{\mathrm{H}}-10$, which reports on the TGF- $\alpha$-type coiled coil. Cells were treated with $1 \mu \mathrm{M}$ of the indicated hydrocarbon-stapled peptide for $1 \mathrm{~h}$, stimulated with $16.7 \mathrm{nM}$ EGF or TGF- $\alpha$ for $30 \mathrm{~min}$, and labeled with ReAsH. Plot shows the change in ReAsH fluorescence of ' $n$ ' cells after correction for differences in expression. Error bars, s.e.m., ${ }^{* *} \mathrm{p}<0.01, * * * * \mathrm{p}<0.0001$; one-way ANOVA with Bonferroni post-analysis accounting for multiple comparisons 

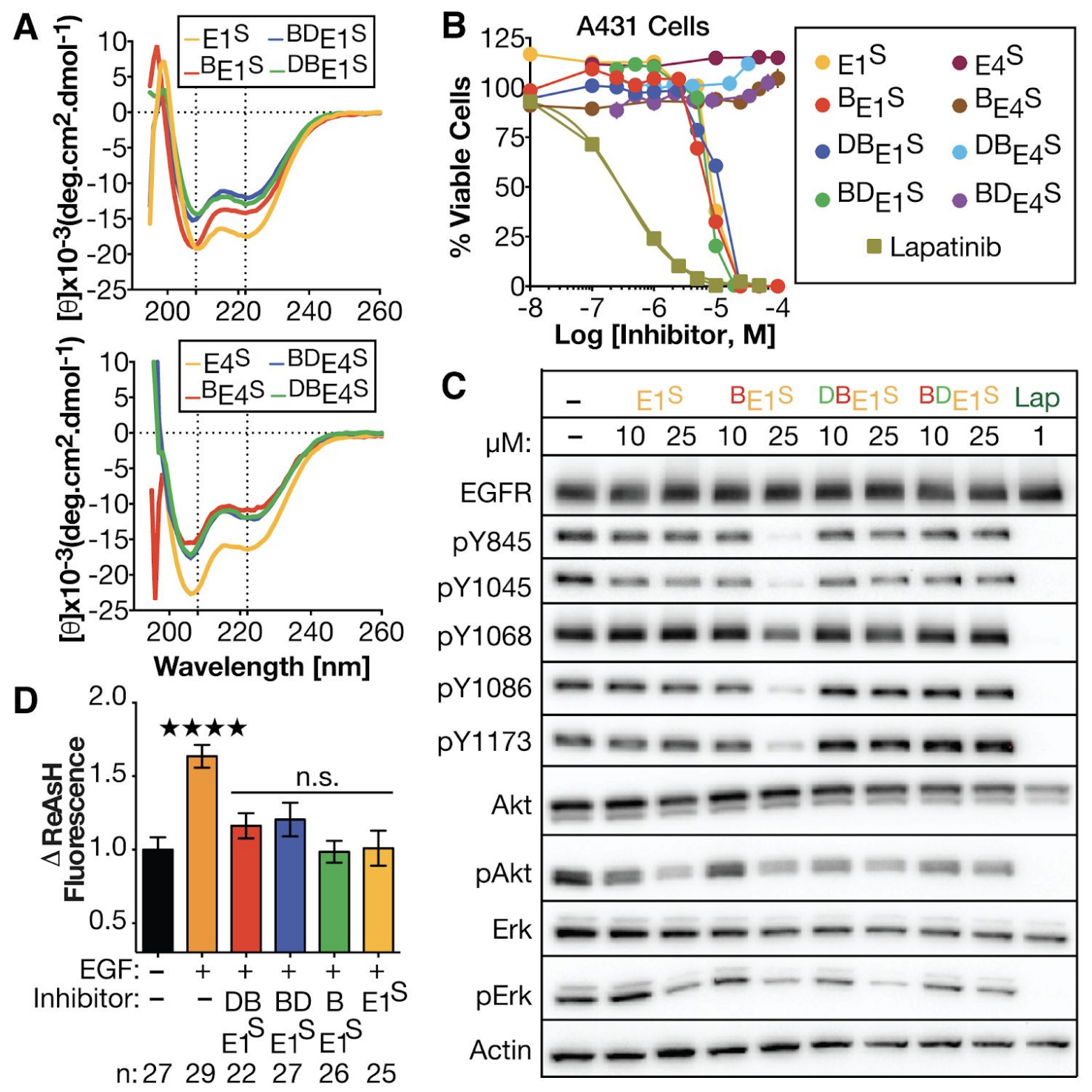

Figure S2, Related to Figure 3. Validation of affinity and photoaffinity probes related to $\mathrm{E} 1^{\mathrm{S}}$ and $\mathrm{E} 4^{\mathrm{S}}$. (A) Circular dichroism spectra of $E 1^{\mathrm{S}}$ and $\mathrm{E} 4^{\mathrm{S}}$ affinity and photoaffinity probes $(25 \mu \mathrm{M})$ in $\mathrm{dPBS} \mathrm{pH} 7.0$. Plots represent background subtracted averages of six scans. (B) Effect of $\mathrm{E} 1^{\mathrm{S}}$ and $\mathrm{E} 4^{\mathrm{S}}$ affinity and photoaffinity probes on A431 cell proliferation. Plots illustrate \% viable A431 cells $18 \mathrm{~h}$ after treatment with indicated ligands. Viability was assessed as described in Figure S1. (C) Western blot monitoring the effect of $\mathrm{E} 1^{\mathrm{S}}$ affinity and photoaffinity probes on EGFR phosphorylation and downstream targets in A431 cells. Lapatinib (Lap) was used as a control. Cells were incubated with the indicated ligand for $2 \mathrm{~h}$, followed by addition of $1.67 \mathrm{nM}$ EGF for $5 \mathrm{~min}$, then lysed and subjected to reducing SDS-PAGE (10\% polyacrylamide) and immuno- blotted to detect the indicated protein species (D) Effect of $\mathrm{E} 1^{\mathrm{S}}$ affinity and photoaffinity probes on assembly of the EGF-type JM coiled-coil using bipartite tetracysteine display. CHO-K1 cells were transfected with EGFR $\mathrm{CC}_{\mathrm{H}^{-}}$, which reports on assembly of the EGF-type JM coiled coil, treated with $1 \mu \mathrm{M}$ ligand for $1 \mathrm{~h}$, stimulated with 16.7nM EGF or TGF $\alpha$ for $30 \mathrm{~min}$, and labeled with ReAsH. Plot shows the change in ReAsH fluorescence of ' $n$ ' cells after correction for differences in expression. Errors represent standard error of the mean: $* * * * p<0.0001$; one-way ANOVA with Bonferroni post analysis accounting for multiple comparisons. 
A $-U V$

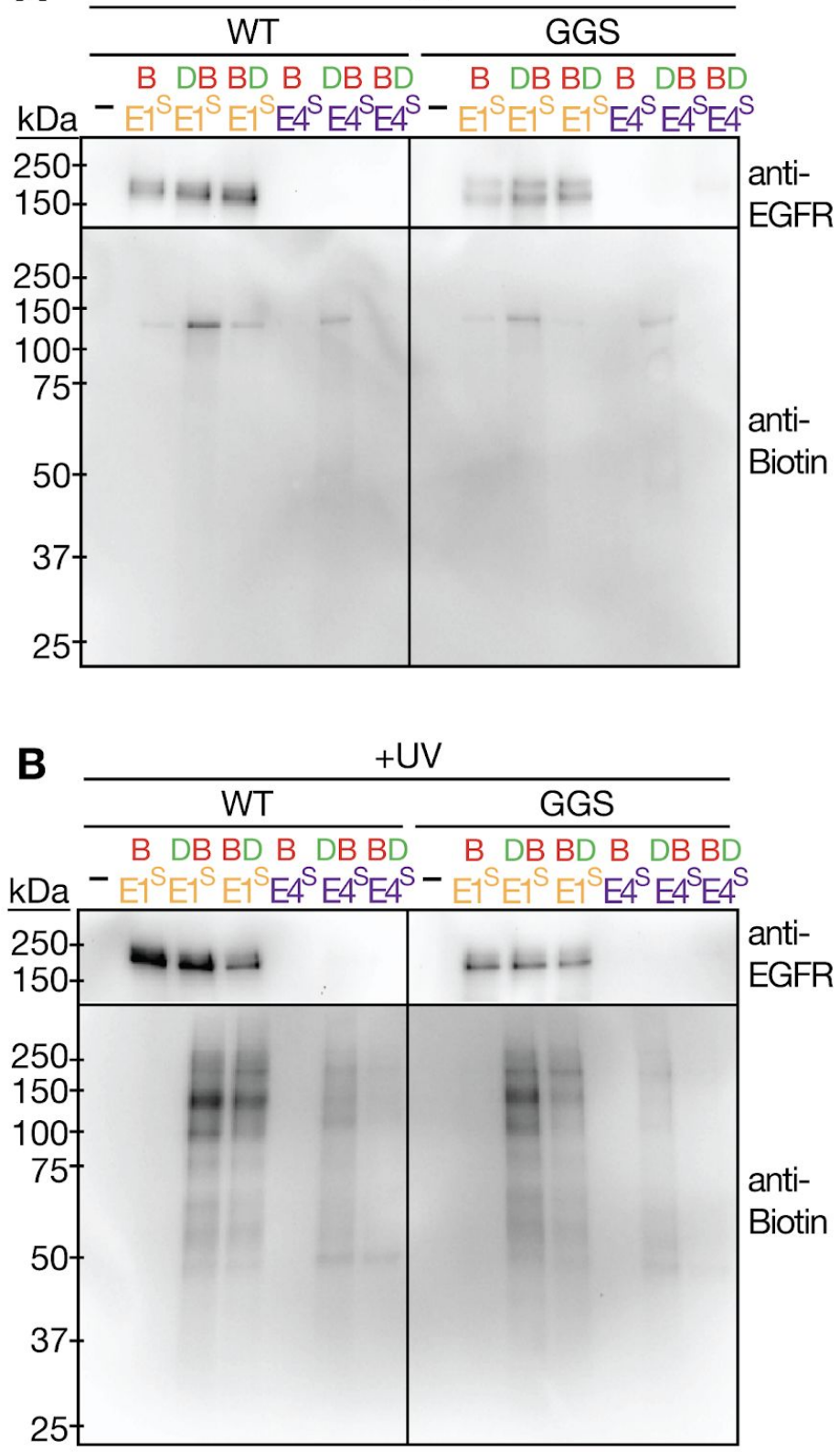

Figure S3, Related to Figure 3 \& 4. Photo-affinity labeling experiments confirm that an intact, native sequence juxtamembrane segment is required for a high affinity interaction between $\mathrm{E} 1^{\mathrm{S}}$ and EGFR. $(\mathrm{A}, \mathrm{B})$ uncropped gel images identical to Figure 3B and 3C of the Main Text. 
A MSPILGYWKIKGLVQPTRLLEYLEEKYEE HLYERDEGDKWRNKKFELGLEFPNLPYYI DGDVKLTQSMAIIRYIADKHNMLGGCPKE RAEISMLEGAVLDIRYGVSRIAYSKDFETLK VDFLSKLPEMLKMFKDRLCHKTYLNGDH VTHPDFMLYDALDWLYMDPMCLDAFPKL VCFKKRIEAIPQIDKYLKSSKYIAWPLQGW QATFGGGDHPPKSDPMRRRHIVRKRTLR RLLQERELVEPLTPSGEAPNQALLRILKE TEFKKIKVLGSGAFGTVYKGLWIPEGEK VKIPVAIKELREATSPKANKEILDEAYVM ASVDNPHVCRLLGICLTSTVQLITQLMPF GCLLDYVREHKDNIGSQYLLNWCVQIAK GMNYLEDRRLVHRDLAARNVLVKTPQH VKITDFGLAKLLGAEEKEYHAEGGKVPIK WMALESILHRIYTHQSDVWSYGVTVWEL MTFGSKPYDGIPASEISSILEKGERLPQP PICTIDVYMIMVKCWMIDADSRPKFRELI IEFSKMARDPQRYLVIQGDERMHLPSPT DSNFYRALMDEEDMDDVVADEYLIPQ QGFFSSPSTSRTPLLSSLSATSNNSTVAC IDRNGLQSCPIKEDSFLQRYSSDPTGALT EDSIDDTFLPVPEYINQSVPKRPAGSVQN PVYHNQPLNPAPSRDPHYQDPHSTAVG NPEYLNTVQPTCVNSTFDSPAHWAQKG SHQISLDNPDYQQDFFPKEAKPNGIFKG STAENAEYLRVAPQSSEFIGA

371 unique results from 6173 spectra

D MSPILGYWKIKGLVQPTRШLYLEEKYEE HLYERDEGDKWRNKKFELGLEFPNLPYYI DGDVKLTQSMAIIRYIADKHNMLGGCPKE RAEISMLEGAVLDIRYGVSRIAYSKDFETLK VDFLSKLPEMLKMFKDRLCHKTYLNGDH VTHPDFMLYDALDWLYMDPMCLDAFPKL VCFKKRIEAIPQIDKYLKSSKYIAWPLQGW QATFGGGDHPPKSDPMRRRHIVRKRTLR RLLQERELVEPLTPSGEAPNQALLRILKE TEFKKIKVLGSGAFGTVYKGLWIPEGEK VKIPVAIKELREATSPKANKEILDEAYVM ASVDNPHVCRLLGICLTSTVQLITQLMPF GCLLDYVREHKDNIGSQYLLNWCVQIAK GMNYLEDRRLVHRDLAARNVLVKTPQH VKITDFGLAKLLGAEEKEYHAEGGKVPIK WMALESILHRIYTHQSDVWSYGVTVWEL MTFGSKPYDGIPASEISSILEKGERLPQP PICTIDVYMIMVKCWMIDADSRPKFRELI IEFSKMARDPQRYLVIQGDERMHLPSPT DSNFYRALMDEEDMDDVVDADEYLIPQ QGFFSSPSTSRTPLLSSLSATSNNSTVAC IDRNGLQSCPIKEDSFLQRYSSDPTGALT EDSIDDTFLPVPEYINQSVPKRPAGSVQN PVYHNQPLNPAPSRDPHYQDPHSTAVG NPEYLNTVQPTCVNSTFDSPAHWAQKG SHQISLDNPDYQQDFFPKEAKPNGIFKG STAENAEYLRVAPQSSEFIGA

321 unique results from 4318 spectra
B MSPILGYWKIKGLVQPTRLLLEYLEEKYEE HLYERDEGDKWRNKKFELGLEFPNLPYYI DGDVKLTQSMAIIRYIADKHNMLGGCPKE RAEISMLEGAVLDIRYGVSRIAYSKDFETLK VDFLSKLPEMLKMFKDRLCHKTYLNGDH VTHPDFMLYDALDWLYMDPMCLDAFPKL VCFKKRIEAIPQIDKYLKSSKYIAWPLQGW QATFGGGDHPPKSDPMRRRHIVRKRTLR RLLQERELVEPLTPSGEAPNQALLRILKE TEFKKIKVLGSGAFGTVYKGLWIPEGEK VKIPVAIKELREATSPKANKEILDEAYVM ASVDNPHVCRLLGICLTSTVQLITQLMPF GCLLDYVREHKDNIGSQYLLNWCVQIAK GMNYLEDRRLVHRDLAARNVLVKTPQH VKITDFGLAKLLGAEEKEYHAEGGKVPIK WMALESILHRIYTHQSDVWSYGVTVWEL MTFGSKPYDGIPASEISSILEKGERLPQP PICTIDVYMIMVKCWMIDADSRPKFRELI IEFSKMARDPQRYLVIQGDERMHLPSPT DSNFYRALMDEEDMDDVVADEYLIPQ QGFFSSPSTSRTPLLSSLSATSNNSTVAC IDRNGLQSCPIKEDSFLQRYSSDPTGALT EDSIDDTFLPVPEYINQSVPKRPAGSVQN PVYHNQPLNPAPSRDPHYQDPHSTAVG NPEYLNTVQPTCVNSTFDSPAHWAQKG SHQISLDNPDYQQDFFPKEAKPNGIFKG STAENAEYLRVAPQSSEFIGA

570 unique results from 7871 spectra

E MSPILGYWKIKGLVQPTRLLLEYLEEKYEE HLYERDEGDKWRNKKFELGLEFPNLPYYI DGDVKLTQSMAIIRYIADKHNMLGGCPKE RAEISMLEGAVLDIRYGVSRIAYSKDFETLK VDFLSKLPEMLKMFKDRLCHKTYLNGDH VTHPDFMLYDALDWLYMDPMCLDAFPKL VCFKKRIEAIPQIDKYLKSSKYIAWPLQGW QATFGGGDHPPKSDPMRRRHIVRKRTLR RLLQERELVEPLTPSGEAPNQALLRILKE TEFKKIKVLGSGAFGTVYKGLWIPEGEK VKIPVAIKELREATSPKANKEILDEAYVM ASVDNPHVCRLLGICLTSTVQLITQLMPF GCLLDYVREHKDNIGSQYLLNWCVQIAK GMNYLEDRRLVHRDLAARNVLVKTPQH VKITDFGLAKLLGAEEKEYHAEGGKVPIK WMALESILHRIYTHQSDVWSYGVTVWEL MTFGSKPYDGIPASEISSILEKGERLPQP PICTIDVYMIMVKCWMIDADSRPKFRELI IEFSKMARDPQRYLVIQGDERMHLPSPT DSNFYRALMDEEDMDDVDADEYLIPQ QGFFSSPSTSRTPLLSSLSATSNNSTVAC IDRNGLQSCPIKEDSFLQRYSSDPTGALT EDSIDDTFLPVPEYINQSVPKRPAGSVQN PVYHNQPLNPAPSRDPHYQDPHSTAVG NPEYLNTVQPTCVNSTFDSPAHWAQKG SHQISLDNPDYQQDFFPKEAKPNGIFKG STAENAEYLRVAPQSSEFIGA

372 unique results from 5480 spectra
C MSPILGYWKIKGLVQPTRLLLEYLEEKYEE HLYERDEGDKWRNKKFELGLEFPNLPYYI DGDVKLTQSMAIIRYIADKHNMLGGCPKE RAEISMLEGAVLDIRYGVSRIAYSKDFETLK VDFLSKLPEMLKMFKDRLCHKTYLNGDH VTHPDFMLYDALDWLYMDPMCLDAFPKL VCFKKRIEAIPQIDKYLKSSKYIAWPLQGW QATFGGGDHPPKSDPMRRRHIVRKRTLR RLLQERELVEPLTPSGEAPNQALLRILKE TEFKKIKVLGSGAFGTVYKGLWIPEGEK VKIPVAIKELREATSPKANKEILDEAYVM ASVDNPHVCRLLGICLTSTVQLITQLMPF GCLLDYVREHKDNIGSQYLLNWCVQIAK GMNYLEDRRLVHRDLAARNVLVKTPQH VKITDFGLAKLLGAEEKEYHAEGGKVPIK WMALESILHRIYTHQSDVWSYGVTVWEL MTFGSKPYDGIPASEISSILEKGERLPQP PICTIDVYMIMVKCWMIDADSRPKFRELI IEFSKMARDPQRYLVIQGDERMHLPSPT DSNFYRALMDEEDMDDVVDADEYLIPQ QGFFSSPSTSRTPLLSSLSATSNNSTVAC IDRNGLQSCPIKEDSFLQRYSSDPTGALT EDSIDDTFLPVPEYINQSVPKRPAGSVQN PVYHNQPLNPAPSRDPHYQDPHSTAVG NPEYLNTVQPTCVNSTFDSPAHWAQKG SHQISLDNPDYQQDFFPKEAKPNGIFKG STAENAEYLRVAPQSSEFIGA

286 unique results from 3444 spectra

Figure S4, Related to Figure 5. Sequence coverage of EGFR645-1186 after treatment with trypsin. 0.15 $\mu \mathrm{M}$ of EGFR645-1186 was incubated with (A) 0 or 1 equiv of (B) ${ }^{\mathrm{DB}} \mathrm{E} 1^{\mathrm{S}},(\mathrm{C}){ }^{\mathrm{BD}} \mathrm{E} 1^{\mathrm{S}}$, (D) ${ }^{\mathrm{DB}} \mathrm{E} 4{ }^{\mathrm{S}}$, or $(\mathrm{E}){ }^{\mathrm{BD}} \mathrm{E}{ }^{\mathrm{S}}$ for $2 \mathrm{~h}$ at $4^{\circ} \mathrm{C}$, irradiated $(365 \mathrm{~nm}, 10 \mathrm{~min})$, and subjected to MS sample preparation, trypsin digestion, injection into LC-MS/MS, followed by MS/MS data analysis using MyriMatch/BumberDash (v.1.4.115) and IDPicker (v.2.6.271.0). The entire sequence of GST-EGFR645-1186 is shown; residues highlighted in yellow were found among the tryptic peptides. EGFR residues are represented by bold font. 

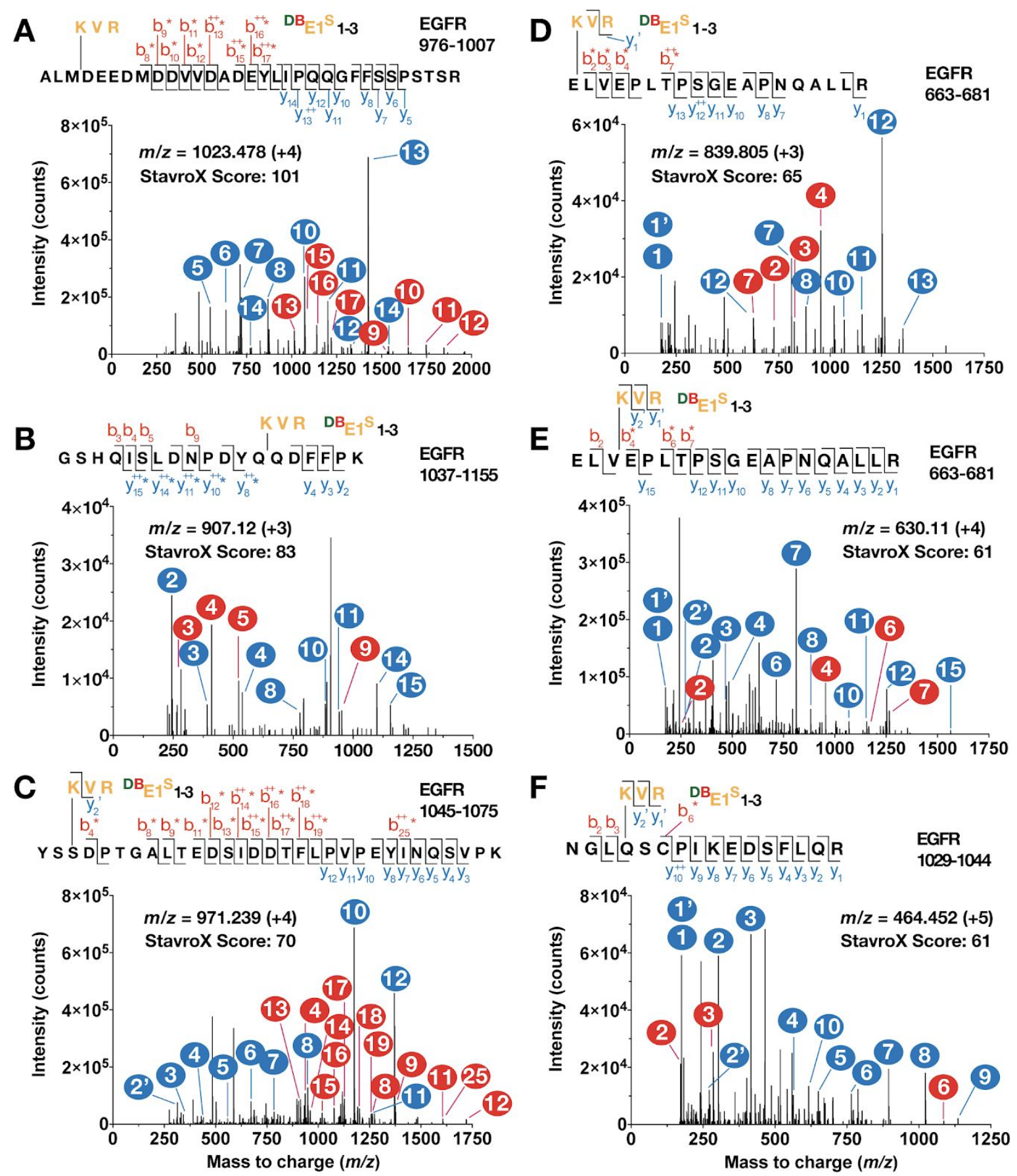

Figure S5, Related to Figure 5. MS/MS spectra of high-scoring tryptic peptides that result from EGFR645-1186 cross-linked at various positions to ${ }^{\mathrm{DB}} \mathrm{E} 1^{\mathrm{S}} .0 .15 \mu \mathrm{M}$ EGFR645-1186 was incubated with/ without 1 eq ${ }^{\mathrm{DB}} \mathrm{E} 1^{\mathrm{S}}$ for $2 \mathrm{~h}$ at $4 \mathrm{C}$, irradiated $(365 \mathrm{~nm}, 10 \mathrm{~min})$, then subjected to MS sample preparation, trypsin digestion, injection into LC-MS/MS, followed by MS/MS data analysis using StavroX. Manually filtered, highest scoring cross-linked species are listed in Table S3. MS/MS spectra of select cross-linked species, corresponding to those ranked by StavroX with scores of (A) 101, (B) 83, (C) 70, (D) 65, (E) 61, and (F) 61, are shown. 


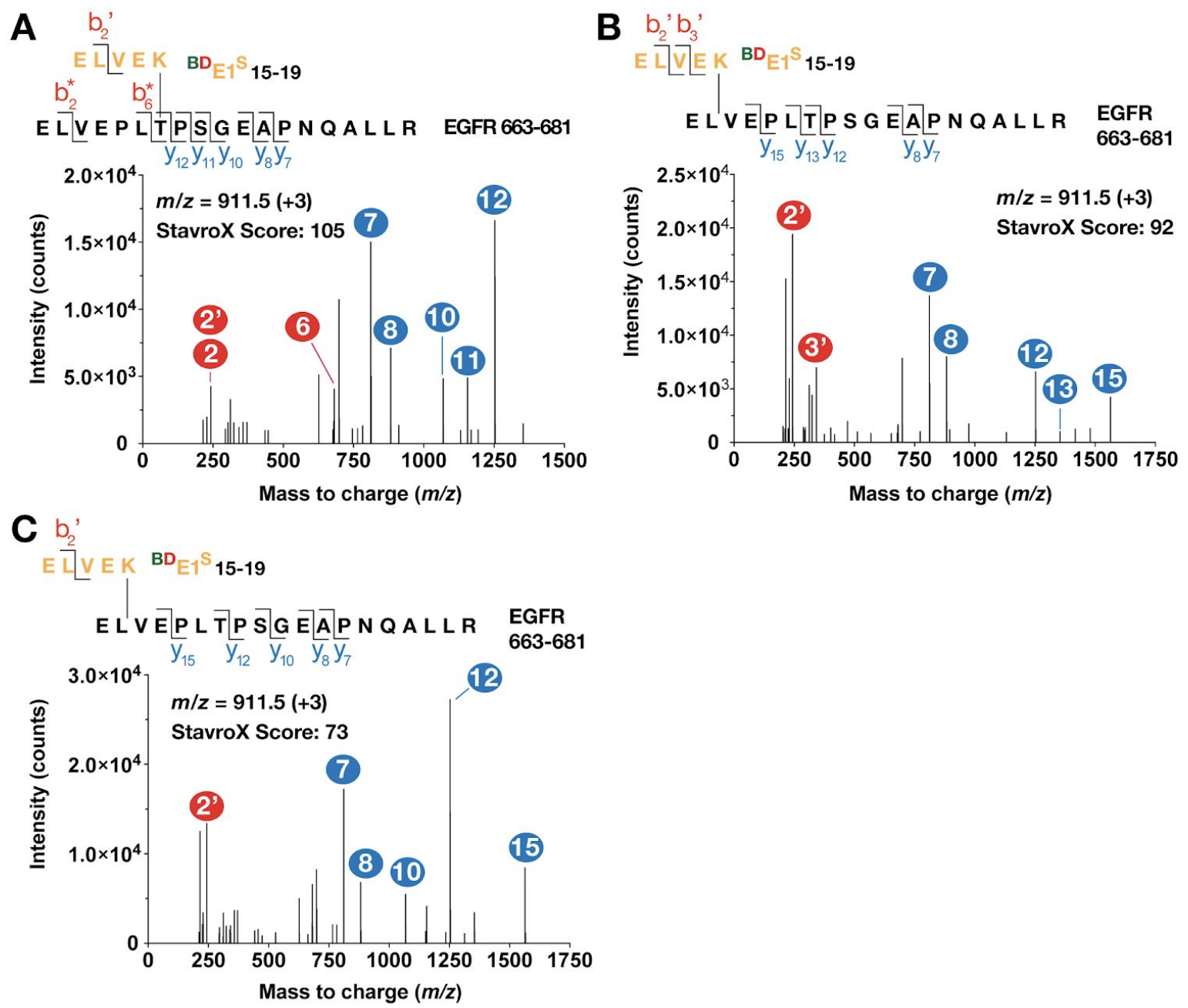

Figure S6, Related to Figure 5. MS/MS spectra of high-scoring tryptic peptides that result from EGFR645-1186 cross-linked at various positions to ${ }^{\mathrm{BD}} \mathrm{E} 1^{\mathrm{S}}$. $0.15 \mu \mathrm{M}$ of EGFR645-1186 was incubated with or without 1 eq of ${ }^{\mathrm{BD}} \mathrm{E} 1^{\mathrm{S}}$ for $2 \mathrm{~h}$ at $4 \mathrm{C}$, irradiated ( $\left.365 \mathrm{~nm}, 10 \mathrm{~min}\right)$, then subjected to MS sample preparation, trypsin digestion, injection into LC-MS/MS, followed by MS/MS data analysis using StavroX. Manually filtered, highest scoring cross-linked species are listed in Table S3. MS/MS spectra of select cross-linked species, corresponding to those that were ranked by StavroX with scores of (A) 105, (B) 92 and (C) 73, are shown. 


\section{Supplementary Tables}

Table S1, Related to Figures 1, 2, 3, and 4. Sequences, predicted, and observed masses of peptides and hydrocarbon-stapled peptides studied herein.

\begin{tabular}{|c|c|c|c|}
\hline Peptide & Peptide Sequence & $\begin{array}{l}\text { Predicted } \\
\text { Mass (Da) }\end{array}$ & $\begin{array}{l}\text { Observed } \\
\text { Mass (Da) }\end{array}$ \\
\hline $\mathrm{JM}^{\mathrm{WT}}$ & HAcN - VRKRTLRRLLQERELVE & 2235 & 2237.2 \\
\hline $\mathrm{E} 1^{\mathrm{S}}$ & HAcN - VRKRR ${ }_{8}$ LRRLLQS $_{5}$ RELVE & 2298 & 2297.4 \\
\hline $\mathrm{E} 2^{\mathrm{S}}$ & HAcN - VRKRTLRS ${ }_{5}$ LLQS $_{5}$ RELVE & 2201 & 2200.3 \\
\hline $\mathrm{E} 3^{\mathrm{S}}$ & $\mathrm{HAcN}-\mathrm{VRKRTLS}_{5} \mathrm{RLLS}_{5}$ ERELVE & 2202 & 2201.2 \\
\hline $\mathrm{E} 4^{\mathrm{S}}$ & $\mathrm{HAcN}-\mathrm{VRKRTLRR}_{5} \mathrm{LLS}_{5} \mathrm{ERELVE}$ & 2202 & 2201.3 \\
\hline $\mathrm{T} 1^{\mathrm{s}}$ & $\mathrm{HAcN}-\mathrm{VRKRTS}_{5} \mathrm{RRLS}_{5} \mathrm{QERELVE}$ & 2260 & 2259.2 \\
\hline $\mathrm{T} 2^{\mathrm{S}}$ & HAcN - VRKRTLRRLS 5 QERS $_{5}$ LVE & 2243 & 2242.0 \\
\hline $\mathrm{T}^{\mathrm{S}}$ & HAcN - VRKRTR ${ }_{5}$ RRS $_{5}$ LQERELVE & 2260 & 2259.4 \\
\hline $\mathrm{T} 4^{\mathrm{S}}$ & $\mathrm{HAcN}-\mathrm{VRKRS}_{5} \mathrm{LRRS}_{5} \mathrm{LQERELVE}$ & 2272 & 2271.3 \\
\hline $\mathrm{E} 1_{\Delta \mathrm{L}}^{\mathrm{s}}$ & $\mathrm{HAcN}-\mathrm{VRKRR}_{8} \mathrm{ARRAAQS}_{5} \mathrm{RELVE}$ & 2172 & 2171.2 \\
\hline${ }^{\mathrm{B}} \mathrm{JM}^{\mathrm{WT}}$ & (LC-Biotin)HN - VRKRTLRRLLQERELVE & 2531 & 2532.4 \\
\hline${ }^{\mathrm{B}} \mathrm{E} 1^{\mathrm{S}}$ & $\left(\right.$ LC-Biotin)HN - VRKRR ${ }_{8}$ LRRLLQS $_{5}$ RELVE & 2594 & 2594.6 \\
\hline${ }^{\mathrm{B}} \mathrm{E} 4^{\mathrm{S}}$ & (LC-Biotin)HN - VRKRTLRR ${ }_{5}$ LLS $_{5}$ ERELVE & 2498 & 2498.4 \\
\hline${ }^{\mathrm{B}} \mathrm{T} 1^{\mathrm{S}}$ & (LC-Biotin)HN - VRKRTS RRLS $_{5}$ QERELVE & 2556 & 2556.4 \\
\hline${ }^{\mathrm{B}} \mathrm{E} 1_{\Delta \mathrm{L}}^{\mathrm{s}}$ & (LC-Biotin)HN - VRKRR ${ }_{8} \mathrm{ARRAAQS}_{5} \mathrm{RELVE}$ & 2468 & 2468.4 \\
\hline${ }^{\mathrm{DB}} \mathrm{E} 1^{\mathrm{S}}$ & $\mathrm{H}_{2} \mathrm{~N}-\mathrm{K}$ (Diazirine)VRKRR ${ }_{8}$ LRRLLQS $_{5} \mathrm{RELVEK}$ (LC-Biotin) & 2960 & 2960.8 \\
\hline${ }^{\mathrm{BD}} \mathrm{E} 1^{\mathrm{S}}$ & $\mathrm{H}_{2} \mathrm{~N}-\mathrm{K}\left(\right.$ LC-Biotin)VRKRR ${ }_{8}$ LRRLLQS $_{5}$ RELVEK(Diazirine) & 2960 & 2961.2 \\
\hline${ }^{\mathrm{DB}} \mathrm{E} 4^{\mathrm{S}}$ & $\mathrm{H}_{2} \mathrm{~N}-\mathrm{K}\left(\right.$ Diazirine)VRKRTLRR ${ }_{5} \mathrm{LLS}_{5}$ ERELVEK(LC-Biotin) & 2864 & 2864.6 \\
\hline${ }^{\mathrm{BD}} \mathrm{E} 4^{\mathrm{S}}$ & $\mathrm{H}_{2} \mathrm{~N}-\mathrm{K}\left(\right.$ LC-Biotin)VRKRTLRR ${ }_{5}$ LLS $_{5}$ ERELVEK(Diazirine) & 2864 & 2864.6 \\
\hline $\mathrm{FITC}_{\mathrm{E}} 1^{\mathrm{S}}$ & $\mathrm{H}_{2} \mathrm{~N}-\mathrm{K}(\mathrm{FITC}) \mathrm{VRKRR}_{8}$ LRRLLQS $_{5}$ RELVE & 2773 & 2772.5 \\
\hline
\end{tabular}

Notes: All synthetic peptides were prepared as C-terminal amides and were acetylated at the $\mathrm{N}$-terminus. $\mathrm{R}_{8}$ represents (R)-2-(7-octenyl)alanine, $\mathrm{S}_{5}$ represents (S)-2-(4-pentenyl)-alanine, and $\mathrm{R}_{5}$ represents (R)-2-(4-pentenyl)-alanine ${ }^{1}$. See Experimental procedures for detailed methods. 
Table S2, Related to Figure 4. Spectral count and sequence coverage of GST-tagged EGFR ${ }_{645-1186}$ $\left(E_{\text {GFR }}{ }_{645-1186}\right)$ from indicated treated samples. $\operatorname{EGFR}_{645-1186}(0.15 \mu \mathrm{M})$ was incubated with or without 1 equiv of ${ }^{\mathrm{DB}} \mathrm{E} 1^{\mathrm{S}},{ }^{\mathrm{BD}} \mathrm{E} 1^{\mathrm{S}},{ }^{\mathrm{DB}} \mathrm{E} 4^{\mathrm{S}}$, or ${ }^{\mathrm{BD}} \mathrm{E} 4^{\mathrm{S}}$ for $2 \mathrm{~h}$, irradiated (365 nm, $10 \mathrm{~min}$.), then subjected to MS sample preparation, trypsin digestion, and injection onto a Q Exactive Orbitrap for LC-MS/MS analysis. See Experimental Procedures for details.

\begin{tabular}{|l|c|c|c|}
\hline Sample ID & $\begin{array}{c}\text { Unique } \\
\text { Peptide Count }\end{array}$ & $\begin{array}{c}\text { Spectral } \\
\text { Count }\end{array}$ & $\begin{array}{c}\text { \% Sequence Coverage of } \\
\text { GST-tagged EGFR }_{\text {645-1186 }}\end{array}$ \\
\hline GST-tagged EGFR & $371-1186$ & 6173 & 96.7 \\
\hline GST-tagged EGFR $_{645-1186}+{ }^{\mathrm{DB}} \mathrm{E}{ }^{\mathrm{s}}$ & 570 & 7871 & 97.9 \\
\hline GST-tagged EGFR $_{645-1186}+{ }^{\mathrm{BD}} \mathrm{E} 1^{\mathrm{s}}$ & 286 & 3444 & 93.6 \\
\hline GST-tagged EGFR $_{645-1186}+{ }^{\mathrm{DB}} \mathrm{E} 4^{\mathrm{S}}$ & 321 & 4318 & 96.1 \\
\hline GST-tagged EGFR $_{645-1186}+{ }^{\mathrm{BD}} \mathrm{E} 4^{\mathrm{S}}$ & 372 & 5480 & 94.9 \\
\hline
\end{tabular}


Table S3, Related to Figure 5. Peptides identified by StavroX as resulting from tryptic cleavage of EGFR $_{645-1186}$ cross linked at various positions to ${ }^{\mathrm{DB}} \mathrm{E}^{\mathrm{S}}$. $\mathrm{EGFR}_{645-1186}(0.15 \mu \mathrm{M})$ was incubated with 1 equiv of ${ }^{\mathrm{DB}} \mathrm{E} 1^{\mathrm{S}}$ for $2 \mathrm{~h}$, irradiated ( $365 \mathrm{~nm}, 10 \mathrm{~min}$.), then subjected to MS sample preparation, trypsin digestion, injection into LC-MS/MS, followed by MS/MS data analysis using StavroX ${ }^{2}$, as described in the Experimental Procedures. Only spectra with a StavroX score greater than 60 (corresponding to $<5 \%$ FDR) were considered as potential hits and manually verified as described in the Main Text. The measured and theoretical masses, deviations, and sequences of the tryptic fragments are shown. Residues identified as crosslinked sites are shown in red and in bold. MS/MS spectra corresponding to these identified cross-linked peptides are shown in Figure S5.

\begin{tabular}{|c|c|c|c|c|c|c|}
\hline $\begin{array}{c}\text { StavroX } \\
\text { score }\end{array}$ & $\begin{array}{l}\mathrm{m} / \mathrm{z} \\
\text { meas. }\end{array}$ & $\begin{array}{l}\text { Charge } \\
\text { state }\end{array}$ & {$[\mathrm{M}+\mathrm{H}]^{+}$theor } & $\begin{array}{c}\text { Deviation } \\
\text { [ppm] }\end{array}$ & $\begin{array}{l}\text { Cross-link } \\
\text { on }{ }^{\mathrm{DB}} \mathrm{E} 1^{\mathrm{s}}\end{array}$ & $\begin{array}{l}\text { Sequence of tryptic } \\
\text { peptide }\end{array}$ \\
\hline 101 & 1023.478 & +4 & 4090.89 & 0.26 & KVR & $\begin{array}{l}\text { 976-ALMDEEDMDD } \\
\text { VVDADEYLIPQQGF } \\
\text { FSSPSTSR-1007 }\end{array}$ \\
\hline 93 & 818.983 & +5 & 4090.89 & -0.65 & KVR & $\begin{array}{l}\text { 976-ALMDEEDMDD } \\
\text { VVDADEYLIPQQGF } \\
\text { FSSPSTSR-1007 }\end{array}$ \\
\hline 93 & 1023.478 & +4 & 4090.89 & -0.11 & KVR & $\begin{array}{l}\text { 976-ALMDEEDMDD } \\
\text { VVDADEYLIPQQGF } \\
\text { FSSPSTSR-1007 }\end{array}$ \\
\hline 90 & 1364.301 & +3 & 4090.89 & -0.17 & KVR & $\begin{array}{l}\text { 976-ALMDEEDMDD } \\
\text { VVDADEYLIPQQGF } \\
\text { FSSPSTSR-1007 }\end{array}$ \\
\hline 88 & 1023.478 & +4 & 4090.89 & 0.88 & KVR & $\begin{array}{l}\text { 976-ALMDEEDMDD } \\
\text { VVDADEYLIPQQGF } \\
\text { FSSPSTSR-1007 }\end{array}$ \\
\hline 86 & 1023.478 & +4 & 4090.89 & 1.02 & KVR & $\begin{array}{l}\text { 976-ALMDEEDMDD } \\
\text { VVDADEYLIPQQGF } \\
\text { FSSPSTSR-1007 }\end{array}$ \\
\hline 84 & 1023.478 & +4 & 4090.89 & 0.31 & KVR & $\begin{array}{l}\text { 976-ALMDEEDMDD } \\
\text { VVDADEYLIPQQGF } \\
\text { FSSPSTSR-1007 }\end{array}$ \\
\hline 83 & 907.12 & +3 & 2719.347 & -0.74 & KVR & $\begin{array}{l}\text { 1137-GSHQISLDNPD } \\
\text { YQQDFFPK - } 1155\end{array}$ \\
\hline 83 & 1023.478 & +4 & 4090.89 & 0.43 & KVR & $\begin{array}{l}\text { 976-ALMDEEDMDD } \\
\text { VVDADEYLIPQQGF } \\
\text { FSSPSTSR-1007 }\end{array}$ \\
\hline 83 & 1023.478 & +4 & 4090.89 & 0.92 & KVR & $\begin{array}{l}\text { 976-ALMDEEDMDD } \\
\text { VVDADEYLIPQQGF } \\
\text { FSSPSTSR-1007 }\end{array}$ \\
\hline
\end{tabular}




\begin{tabular}{|c|c|c|c|c|c|c|}
\hline 81 & 1023.478 & +4 & 4090.89 & 0.33 & KVR & $\begin{array}{l}\text { 976-ALMDEEDMDD } \\
\text { VVDADEYLIPQQGF } \\
\text { FSSPSTSR-1007 }\end{array}$ \\
\hline 80 & 1023.478 & +4 & 4090.89 & 0.76 & KVR & $\begin{array}{l}\text { 976-ALMDEEDMDD } \\
\text { VVDADEYLIPQQGF } \\
\text { FSSPSTSR-1007 }\end{array}$ \\
\hline 79 & 1023.478 & +4 & 4090.89 & 0.59 & KVR & $\begin{array}{l}\text { 976-ALMDEEDMDD } \\
\text { VVDADEYLIPQQGF } \\
\text { FSSPSTSR-1007 }\end{array}$ \\
\hline 78 & 1027.47 & +4 & 4106.885 & -6.42 & KVR & $\begin{array}{l}\text { 976-ALMDEEDmDD } \\
\text { VVDADEYLIPQQGF } \\
\text { FSSPSTSR-1007 }\end{array}$ \\
\hline 78 & 1027.47 & +4 & 4106.885 & -6.42 & KVR & $\begin{array}{l}\text { 976-ALMDEEDMDD } \\
\text { VVDADEYLIPQQGF } \\
\text { FSSPSTSR-1007 }\end{array}$ \\
\hline 77 & 818.984 & +5 & 4090.89 & 0.8 & KVR & $\begin{array}{l}\text { 976-ALMDEEDMDD } \\
\text { VVDADEYLIPQQGF } \\
\text { FSSPSTSR - } 1007\end{array}$ \\
\hline 76 & 907.121 & +3 & 2719.347 & 0.56 & KVR & $\begin{array}{l}\text { 1137-GSHQISLDNPD } \\
\text { YQQDFFPK - } 1155\end{array}$ \\
\hline 70 & 971.239 & +4 & 3881.933 & 0.51 & KVR & $\begin{array}{l}\text { 1045-YSSDPTGALTE } \\
\text { DSIDDTFLPVPEYIN } \\
\text { QSVPK-1075 }\end{array}$ \\
\hline 66 & 680.593 & +4 & 2719.347 & 1.06 & KVR & $\begin{array}{l}1137- \\
\text { GSHQISLDNPDYQQ } \\
\text { DFFPK - } 1155\end{array}$ \\
\hline 66 & 844.603 & +5 & 4218.985 & 0.56 & KVRK & $\begin{array}{l}\text { 976-ALMDEEDMDD } \\
\text { VVDADEYLIPQQGF } \\
\text { FSSPSTSR-1007 }\end{array}$ \\
\hline 65 & 839.805 & +3 & 2517.404 & -1.22 & KVR & $\begin{array}{l}\text { 663-ELVEPLTPSGEA } \\
\text { PNQALLR -681 }\end{array}$ \\
\hline 62 & 844.603 & +5 & 4218.985 & 0.86 & KVRK & $\begin{array}{l}\text { 976-ALMDEEDMDD } \\
\text { VVDADEYLIPQQGF } \\
\text { FSSPSTSR-1007 }\end{array}$ \\
\hline 61 & 464.452 & +5 & 2318.229 & 0.09 & KVR & $\begin{array}{l}\text { 1029-NGLQSCPIKED } \\
\text { SFLQR-1044 }\end{array}$ \\
\hline 61 & 630.11 & +4 & 2517.404 & 5.82 & KVR & $\begin{array}{l}\text { 663-ELVEPLTPSGEA } \\
\text { PNQALLR -681 }\end{array}$ \\
\hline
\end{tabular}


Table S4, Related to Figure 5. Peptides identified by StavroX as resulting from tryptic cleavage of EGFR $_{645-1186}$ cross linked at various positions to ${ }^{\mathrm{BD}} \mathrm{E}^{\mathrm{S}}$. $\mathrm{EGFR}_{645-1186}(0.15 \mu \mathrm{M})$ was incubated with 1 equiv of ${ }^{\mathrm{BD}} \mathrm{E} 1^{\mathrm{S}}$ for $2 \mathrm{~h}$, irradiated (365 $\mathrm{nm}, 10 \mathrm{~min}$.), then subjected to MS sample preparation, trypsin digestion, injection into LC-MS/MS, followed by MS/MS data analysis using StavroX ${ }^{2}$, as described in the Experimental Procedures. Only spectra with a StavroX score greater than 67 (corresponding to $<5 \%$ FDR) were considered as potential hits and manually verified as described in the Main Text. The measured and theoretical masses, deviations, and sequences of the tryptic fragments are shown. Residues identified as cross-linked sites are shown in red and in bold. MS/MS spectra corresponding to these identified cross-linked peptides are shown in Figure S6.

\begin{tabular}{|c|c|c|c|c|c|c|}
\hline $\begin{array}{c}\text { StavroX } \\
\text { score }\end{array}$ & $\begin{array}{c}\mathrm{m} / \mathrm{z} \\
\text { meas. }\end{array}$ & $\begin{array}{c}\text { Charge } \\
\text { state }\end{array}$ & {$[\mathrm{M}+\mathrm{H}]_{\text {theor }}^{+}$} & $\begin{array}{c}\text { Deviation } \\
{[\mathrm{ppm}]}\end{array}$ & $\begin{array}{c}\text { Cross-link } \\
\text { on }^{\mathrm{BD}} \mathrm{E}^{\mathrm{s}}\end{array}$ & $\begin{array}{c}\text { Sequence of tryptic } \\
\text { peptide }\end{array}$ \\
\hline 105 & 911.5 & +3 & 2732.472 & 5.05 & ELVEK & $\begin{array}{l}\text { 663-ELVEPLTPSGEAP } \\
\text { NQALLR -681 }\end{array}$ \\
\hline 92 & 911.5 & +3 & 2732.472 & 5.05 & ELVEK & $\begin{array}{l}\text { 663-ELVEPLTPSGEA } \\
\text { PNQALLR -681 }\end{array}$ \\
\hline 73 & 911.5 & +3 & 2732.472 & 5.05 & ELVEK & $\begin{array}{l}\text { 663-ELVEPLTPSGEA } \\
\text { PNQALLR -681 }\end{array}$ \\
\hline
\end{tabular}




\section{Supplemental Experimental Procedures}

\section{Peptide Synthesis, Purification, and Characterization}

Reagents. All purchased reagents were used without further purification. H-Pal Chem Matrix Resin, SigmaCote ${ }^{\circledR}$, and diethyl ether were purchased from Sigma Aldrich (St. Louis, MO). Standard Fluorenylmethyloxycarbonyl (Fmoc)-protected amino acid monomers were purchased from Novabiochem (San Diego, CA). Fmoc-protected olefinic amino acids ((S)-N-Fmoc-2-(4-pentenyl)alanine (Fmoc-S $-\mathrm{OH})$ and (R)-N-Fmoc-2-(7-octenyl)alanine (Fmoc- $\left.\mathrm{R}_{8}-\mathrm{OH}\right)$ ) were purchased from Okeanos Tech Jiangsu Co., Ltd (Jiangsu, P.R. China). Dimethylformamide (DMF), N-methyl pyrolidinone (NMP), trifluoroacetic acid (TFA), N,N,N',N'-tetramethyl-uronium-hexafluoro-phosphate (HBTU), and piperidine were purchased from American Bioanalytical (Natick, MA). Acetic anhydride and triisopropylsilane (TIPS) were purchased from Acros Organics (Fair Lawn, NJ). Diisopropylethylamine (DIPEA) was purchased from Santa Cruz Biotechnology Inc (Santa Cruz, CA). Dichloroethane (DCE) and 6-Chloro-benzotriazole-1-yloxy-tris-pyrrolidinophosphonium hexafluorophosphate (Pyclock) were purchased from EMD Millipore Corp. (Billerica, MA). EZ-Link ${ }^{\circledR}$ NHS-LC-Biotin and NHS-Diazirine were purchased from ThermoScientific, Pierce Biotechnology (Rockford, IL).

Solid phase peptide synthesis. Peptides were synthesized on a $100 \mu \mathrm{mol}$ scale using standard solid-phase

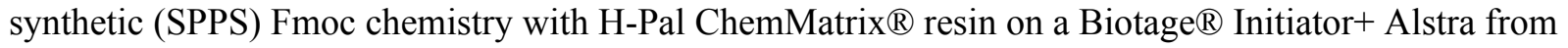
Biotage (Charlotte, NC), as described previously ${ }^{3}$. Peptides containing olefinic residues were stapled (cyclized) on-resin with Grubbs Catalyst I, after N-terminal or N- and C-terminal Lys side chain manual labelings with NHS-LC-Biotin and/or NHS-Diazirine or FITC, as described previously and below ${ }^{3}$. Once the peptide synthesis was complete, the resin was then washed, dried, and cleaved as described previously ${ }^{3}$.

Manual Peptide Labeling. Peptides with the final sequence containing a N-terminal biotin were synthesized by following standard Fmoc-protected SPPS by machine. Peptides (still on resin) with deprotected N-terminus were washed several times with DMF, DCM, DMF, then dry DMF, and treated with 3 eq. of NHS-Diazirine or NHS-LC-Biotin, 6 eq. of dry DIPEA, and approximately $5 \mathrm{~mL}$ of dry DMF, overnight under nitrogen. Resin was then washed several times with DMF, DCM, and DMF. Peptides with the final sequence containing a terminal diazirine and biotin were synthesized with additional precautions: Fmoc-Lys(Mtt)-OH was added to the C-terminus, and Boc-Lys(Fmoc) was added to the N-terminus of the growing peptide, following standard Fmoc-protected SPPS by machine. To deprotect the Mtt group on the C-terminal Lys residue, peptides (still on resin) were incubated with 1\% trifluoroacetic acid in DCM for 1-2 h, with several washes at room temperature. Resin was then washed several times with DMF, DCM, DMF, then dry DMF. Coupling of diazirine or biotin onto the C-terminal Lys residue was then performed by stirring deprotected resin with 3 eq. of NHS-Diazirine or NHS-LC-Biotin, 6 eq. of dry DIPEA, and approximately $5 \mathrm{~mL}$ of dry DMF, overnight under nitrogen. Resin was then washed several times with DMF, DCM, and DMF. To deprotect the Fmoc group on the N-terminal Lys residue, peptides (still on resin) were incubated twice with $20 \%$ piperidine in DMF for 10 min intervals at room temperature. After washing the resin several times with DMF, DCM, DMF, then 
dry DMF, coupling of diazirine or biotin onto the N-terminal Lys residue was performed, using the already described procedure, overnight. Peptides with the final sequence containing a terminal FITC were synthesized with the additional modifications: Boc-Lys(Fmoc) was added to the N-terminus of the growing peptide, following standard Fmoc-protected SPPS by machine. The Fmoc group on the $\mathrm{N}$-terminal Lys residue was deprotected using the already described procedure. After washing the resin several times with DMF, DCM, then DMF, coupling of FITC onto the N-terminal Lys residue was performed by stirring deprotected resin with 7 eq. of FITC, 14 eq. of dry DIPEA, and approximately $3 \mathrm{~mL}$ of DMF, overnight on an orbital shaker.

HPLC Purification of crude peptide product. As previously described ${ }^{3}$, peptide solutions were filtered through $0.42 \mu \mathrm{m}$ filters (EMD Millipore Corporation, Billerica, MA) prior to HPLC. All peptides were purified using a Varian Prostar Prep HPLC system on reverse phase C8 (YMC Basic, BA99S11-1510WT) or Triaryl-C18 (YMC-Triaryl-C18, $150 \mathrm{~mm}$ x10 mm, $5 \mu \mathrm{m}, 12 \mathrm{~nm}$ ) columns over $\mathrm{H}_{2} \mathrm{O}$ /acetonitrile $\left(\mathrm{CH}_{3} \mathrm{CN}\right)$ gradients containing $0.1 \%$ TFA. A gradient of $10-75 \%$ acetonitrile in water over 35 min was used to initially monitor the peptide peaks, and adjusted accordingly to more efficiently elute the isolated peptide peaks. Peptides were detected at $214 \mathrm{~nm}$. Peptide purity was verified using a Shimadzu Analytical HPLC system (ES Industries, West Berlin, NJ; Shimadzu Corporation, Kyoto, Japan) and a C8 reverse phase (Sonoma C8(2), $3 \mu \mathrm{m}, 100 \AA, 10 \mathrm{~cm}$ x $2.1 \mathrm{~nm}$ ) analytical column. A gradient of $15-60 \%$ acetonitrile in water over 15 minutes, with detection at $214 \mathrm{~nm}$, was used.

Mass Spectrometry of Purified Peptides. As previously described ${ }^{3}$, the molecular mass of each peptide was determined by LC-MS, using a Waters XEVO Q-TOF mass spectrometer equipped with an Acquity UPLC BEH C18 1.7 $\mu \mathrm{M}$ column (Milford, MA).

Peptide Concentration Quantification. Purified peptide concentrations were determined by using amino acid analysis (Hydrochloric acid ( $\mathrm{HCl}$ ) hydrolysis) at New England Peptides (Gardner, MA).

Concentrations of purified FITC-labeled peptides were obtained by UV-VIS spectroscopy, monitoring for FITC absorbance at $493 \mathrm{~nm}$ with an extinction coefficient of $68,000 \mathrm{M}^{-1} \mathrm{~cm}^{-1}$.

Circular Dichroism (CD) Analysis. CD analysis on peptides was performed using a Jasco J-810 Spectropolarimeter (Tokyo, Japan) and $1 \mathrm{~mm}$ quartz cuvettes (Hellman USA, Plainview, NY). Peptides were evaluated in Dulbecco's Phosphate Buffered Solution (DPBS) at 25 to $100 \mu \mathrm{M}$ concentrations. Spectra were acquired as the average of six scans at RT from 190 to $260 \mathrm{~nm}$ at a rate of $50 \mathrm{~nm} / \mathrm{min}$, with continuous scanning. Raw CD ellipticity values were converted to molar ellipticity units $\left[10^{3} \cdot \mathrm{deg} \cdot \mathrm{cm}^{2} \cdot \mathrm{dmol}^{-1}\right]$, using the equation [molar ellipticity] $=1000 \mathrm{x}($ Raw CD degrees $) /\left(\mathrm{C}_{\mathrm{r}} \mathrm{x} \mathrm{L}\right)$, where $\mathrm{C}_{\mathrm{r}}$ is the residue molar concentration (molar concentration $\mathrm{x}$ the number of residues within the peptide), and $\mathrm{L}$ is the cell pathlength in $\mathrm{cm}$. 


\section{Experimental Details}

Reagents. 96- and 384-well plates were purchased from Corning Incorporated (Corning, NY). Cell Titer-Glo Luminescent Cell Viability Assay reagents were purchased from the Promega Corporation (Madison, WI). Rabbit anti-EGFR (\#4267), anti-pY1173 (\#4407), anti-pY1086 (\#2220), anti-pY1068 (\#2234), anti-pY1045 (\#2237), anti-pY845 (\#2231), anti-Biotin (\#5597), HRP-conjugated anti-rabbit (\#7074), and HRP-conjugated anti-mouse (\#7076) antibodies were purchased from Cell Signaling Technology (Danvers, MA). Mouse anti-Flag (\#F3165) antibody and Non-Enzymatic Cell Dissociation Solution (\#C5914) were purchased from Sigma Aldrich (St. Louis, MO). Unlabeled EGF was purchased from Fisher Scientific (Suwance, GA). cOmplete Protease Inhibitor Tablets and PhosSTOP Phosphatase Inhibitor Cocktail Tablets were purchased from Roche Applied Science (Indianapolis, IN). Mini-PROTEAN® TGX ${ }^{\mathrm{TM}}$ Precast Gels (10\% Resolving Gel), Clarity ${ }^{\mathrm{TM}}$ Western ECL reagents, and Silver Stain Plus ${ }^{\mathrm{TM}}$ Kit were purchased from Bio-Rad Laboratories, Inc. (Hercules, CA). iBlot Transfer Membranes were purchased from Life Technologies (Carlsbad, CA). Streptavidin Mag-Sepharose beads were purchased from GE Healthcare Biosciences (Piscataway, NJ). Purified, recombinantly-expressed EGFR1-621 (\#SRP 3028), GST-tagged EGFR672-1186 (\#SRP 5023), GST-tagged EGFR645-1186 (\#SRP 0239), and GST (\#SRP5348) were purchased from Sigma-Aldrich (St. Louis, MO). Mass Spectrometry Grade Trypsin/LysC-Mix (\#V5071) was purchased from Promega Corporation (Madison, WI). C18-resin ZipTip ${ }^{\circledR}$ Pipette Tips were purchased from EMD Millipore (Billerica, MA). A431 and CHO-K1 cells were purchased from the American Type Culture Collection (ATCC; Manassas, VA). Plasmid DNA encoding GGS-EGFR was generously donated by Dr. Sarvenaz Sarabipour of the Hristova Laboratory (Johns Hopkins University, Baltimore, MD) ${ }^{4}$. The full-length EGFR containing an N-terminal FLAG tag in a pcDNA 3.1 plasmid, previously described ${ }^{5}$ was donated by the Kuriyan Laboratory.

Cell Culture. All cells were maintained at $37^{\circ} \mathrm{C}, 5 \% \mathrm{CO}_{2}$. A431 cells were maintained in Dulbecco's Modified Eagle Medium (DMEM, Invitrogen) supplemented with 10\% fetal bovine serum (FBS) and pen-strep (PS). CHO-K1 cells were maintained in F12K Medium (Corning) supplemented with 10\% FBS and PS. Transient transfection of CHO-K1 cells was performed via use of the TransIT-CHO Transfection Kit (Mirus Bio LLC). Cell densities were determined with a Cellometer ${ }^{\circledR}$ Auto T4 automated cell counter.

Site-Directed Mutagenesis. EGFR variants (EGFR $\triangle 958$-1029 and EGFR1-998) were generated using the Agilent Technologies QuikChange Site-Directed Mutagenesis Kit (Santa Clara, CA). Mutations were incorporated into the full-length EGFR containing an N-terminal FLAG tag, in a pcDNA3.1 plasmid.

Cell Viability Assay. As previously described ${ }^{3}$, A431 cells (roughly $1 \times 10^{4}, 100 \mu \mathrm{L}$ each) were seeded into 96-well black, clear flat bottom plates (Corning) in full growth medium (DMEM, FBS, PS) and incubated at $37^{\circ} \mathrm{C}$ in $5 \% \mathrm{CO}_{2}$ for 10 hours. Cells were then rinse and incubated overnight in serum-free DMEM, overnight at $37^{\circ} \mathrm{C}$ in $5 \% \mathrm{CO}_{2}$. Cells were then treated for $18 \mathrm{~h}$ with peptides at varying concentration ranges $(0.1$ to $100 \mu \mathrm{M})$, in triplicate. $45 \mu \mathrm{L}$ of CellTiter-Glo reagent was added to each cell, then allowed to shake at room temperature for 2 minutes, then rest for 8 minutes. The cell viability was monitored by recording the luminescence of the plates via a SpectraMax M5 Multi-Detection plate reader. Cell viability for each treatment was calculated by dividing their luminescent reading by the luminescent reading of an untreated well, and plotted, with each point displaying standard error of the mean (SEM) in Prism 5.0 
(GraphPad Software, Inc.). Dose-response curves, as well as the $\mathrm{IC}_{50}$ values, were calculated by using the Sigmoidal, 4PL nonlinear regression function, which utilized the equation $\mathrm{Y}=$

$100 /\left(1+10^{\wedge}((\operatorname{LogIC} 50-\mathrm{X}) *\right.$ HillSlope $\left.\left.)\right)\right)$, where $\mathrm{Y}=\%$ viable cells and $\mathrm{X}=\log [$ inhibitor $]$.in Prism 5.0 (GraphPad Software, Inc.) ${ }^{6}$

Cell Treatment for Immuno-Blot Analysis of Phospho-Inhibition. As previously described ${ }^{3}$, A431 cells (roughly $1.5 \times 10^{6}$ ) were seeded into $100 \mathrm{~mm}$ dishes (BD Falcon), incubated at $37^{\circ} \mathrm{C}$ in $5 \% \mathrm{CO}_{2}$ for 8 hours, followed by serum starving overnight at $37^{\circ} \mathrm{C}$ in $5 \% \mathrm{CO}_{2}$. Cells were then harvested with Non-Enzymatic Cell Dissociation Solution (Sigma), washed with DPBS, then pelleted (200 x g in a plate spinner) into the wells of a U-bottom 96 well plate (roughly $5 \times 10^{5}$ cells per well), then resuspended in $200 \mu \mathrm{L}$ of serum-free DMEM media that had been pre-warmed at $37^{\circ} \mathrm{C}$. The wells were then treated with increasing concentrations of peptides for $2 \mathrm{~h}$ at $37^{\circ} \mathrm{C}$. After treatment, cells were resuspended in serum-free DMEM media $(200 \mu \mathrm{L})$ that was supplemented with EGF $(10 \mathrm{ng} / \mathrm{mL})$, and incubated at $37^{\circ} \mathrm{C}$ in $5 \% \mathrm{CO}_{2}$ for $5 \mathrm{~min}$. After growth factor-stimulation, the cells were pelleted $(200 \mathrm{x} \mathrm{g})$ and lysed with 100 $\mu \mathrm{L}$ lysis buffer (50 mM Tris, $150 \mathrm{mM} \mathrm{NaCl}, 1 \mathrm{mM}$ EDTA, $1 \mathrm{mM} \mathrm{NaF}, 1 \%$ Triton X-100, pH 7.5, supplemented with one protease inhibitor tablet and one phosphatase inhibitor tablet per $10 \mathrm{~mL}$ ) on ice for $1.5 \mathrm{~h}$ (Roche). Supernatant from cleared cell lysates (cell lysates centrifuged for $5 \mathrm{~min}$ at 20,000 x g) was used in SDS-PAGE gel analysis, by adding supernatant to gel-loading dye $(2 \% \mathrm{w} / \mathrm{v}$ sodium dodecyl sulfate (SDS), 10\% glycerol, 0.01\% bromophenol blue, $50 \mathrm{mM}$ Tris- $\mathrm{HCl}, \mathrm{pH} 6.8,1 \% \beta$-mercaptoethanol) for subsequent loading onto 10\% polyacrylamide gels (BioRad) for SDS-PAGE. Gels were then transferred to PVDF membranes using an iBlot apparatus (Invitrogen).

Immuno-Blot Analysis. As previously described ${ }^{3}$, PVDF iBlot transfer membranes were blocked with $5 \%$ milk in TBS-T (50 mM Tris, $150 \mathrm{mM} \mathrm{NaCl}, 0.1 \%$ Tween, $\mathrm{pH} 7.4$ ) for $1 \mathrm{~h}$, followed by incubation with primary antibodies for $16-18$ hours at $4^{\circ} \mathrm{C}$. The membranes were washed three times with TBS-T (1 x 5min, 2 x $10 \mathrm{~min}$ ) and exposed to secondary HRP-conjugated antibody for 1-2 hours. The membranes were washed using TBS-T, as described, then developed using Clarity ${ }^{\mathrm{TM}}$ Western ECL reagents (Bio-Rad). Chemiluminescent detection was performed using a ChemiDoc XRS+ (BioRad). Total band intensities were quantified with the gel analysis function of ImageJ, version 1.46r, and normalized to the untreated sample band intensities (NIH, USA).

Surface ReAsH Labeling Studies, i.e. Bipartite Tetracysteine Display Assay. CHO-K1 cells were treated as previously described ${ }^{3}$, adding a one hour incubation of the indicated stapled peptide inhibitor $(1 \mu \mathrm{M})$ in ATP inhibition media prior to growth factor stimulation ${ }^{5}$.

Total Internal Reflectance Fluorescence (TIRF) Microscopy. TIRF Microscopy images were obtained using a Leica Microsystems AM TIRF MC DMI6000B with an EM-CCD camera (Hamamatsu), as previously reported ${ }^{3,5}$. TIRF-Microscopy images were analyzed by ImageJ, version 1.46r, and normalized to the cell samples that were not treated. Resulting ReAsH fold increases, relative to the untreated cell samples, were then analyzed via one-way ANOVA with Bonferroni post-analysis, accounting for multiple comparisons. 


\section{References}

(1) Schafmeister, C. E.; Po, J.; Verdine, G. L. An All-Hydrocarbon Cross-Linking System for Enhancing the Helicity and Metabolic Stability of Peptides. J. Am. Chem. Soc. 2000, 122 (24), 5891-5892. https://doi.org/10.1021/ja000563a.

(2) Götze, M.; Pettelkau, J.; Schaks, S.; Bosse, K.; Ihling, C. H.; Krauth, F.; Fritzsche, R.; Kühn, U.; Sinz, A. StavroX - A Software for Analyzing Crosslinked Products in Protein Interaction Studies. $J$. Am. Soc. Mass Spectrom. 2012, 23 (1), 76-87. https://doi.org/10.1021/jasms.8b04122.

(3) Sinclair, J. K.-L.; Denton, E. V.; Schepartz, A. Inhibiting Epidermal Growth Factor Receptor at a Distance. J. Am. Chem. Soc. 2014, 136 (32), 11232-11235. https://doi.org/10.1021/ja504076t.

(4) He, L.; Hristova, K. Consequences of Replacing EGFR Juxtamembrane Domain with an Unstructured Sequence. Sci. Rep. 2012, 2 (1), 854. https://doi.org/10.1038/srep00854.

(5) Scheck, R. A.; Lowder, M. A.; Appelbaum, J. S.; Schepartz, A. Bipartite Tetracysteine Display Reveals Allosteric Control of Ligand-Specific EGFR Activation. ACS Chem Biol 2012, 7 (8), 1367-1376. https://doi.org/10.1021/cb300216f.

(6) Gadagkar, S. R.; Call, G. B. Computational Tools for Fitting the Hill Equation to Dose-Response Curves. J. Pharmacol. Toxicol. Methods 2015, 71, 68-76.

https://doi.org/10.1016/j.vascn.2014.08.006. 